Abstracta Iranica Iranica

Revue bibliographique pour le domaine irano-aryen

Volume 32-33 | 2013

Comptes rendus des publications de 2009-2010

\title{
Barbara Kaim. Bone Reliefs from Fire Temple at Mele Hairam, South-West Turkmenistan
}

\section{Rémy Boucharlat}

\section{OpenEdition}

1 Journals

Édition électronique

URL : http://journals.openedition.org/abstractairanica/40543

DOI : 10.4000/abstractairanica.40543

ISSN : 1961-960X

\section{Éditeur :}

CNRS (UMR 7528 Mondes iraniens et indiens), Éditions de l'IFRI

\section{Édition imprimée}

Date de publication : 1 décembre 2013

ISSN : 0240-8910

\section{Référence électronique}

Rémy Boucharlat, «Barbara Kaim. Bone Reliefs from Fire Temple at Mele Hairam, South-West Turkmenistan », Abstracta Iranica [En ligne], Volume 32-33 | 2013, document 179, mis en ligne le 01 juillet 2016, consulté le 05 octobre 2020. URL : http://journals.openedition.org/abstractairanica/40543 ; DOI : https://doi.org/10.4000/abstractairanica.40543

Ce document a été généré automatiquement le 5 octobre 2020.

Tous droits réservés 


\title{
Barbara Kaim. Bone Reliefs from Fire Temple at Mele Hairam, South-West Turkmenistan
}

\author{
Rémy Boucharlat
}

\section{RÉFÉRENCE}

Barbara Kaim. « Bone Reliefs from Fire Temple at Mele Hairam, South-West

Turkmenistan ». Iranica Antiqua, 45, 2010, p. 321-335.

1 Découverts dans différentes salles annexes du temple du feu fouillé par la mission turkméno-polonaise de Saraks, tout près de la frontière iranienne ville jumelle de SaraHs), les quatre reliefs sur os présentés ici (hauteur environ $12 \mathrm{~cm}$ ) relèvent de l'art parthe qui s'étend de la Mésopotamie à la Margiane, annonçant l'art sassanide ; l'A. propose de les dater à partir du $\mathrm{II}^{\mathrm{e}} \mathrm{s}$. d.n.è. L'un porte un cavalier, deux autres, presque semblables, un jeune homme nu, le quatrième un roi trônant, très caractéristique par la coiffure qui évoque des monnaies parthes tardives et élyméennes et la position, de face, qui rappelle les reliefs de Bahram II.

\section{AUTEURS}

RÉMY BOUCHARLAT

CNRS, Lyon 